\title{
Tuning the stoichiometry and electrical properties of tantalum oxide thin films
}

\author{
Li, Yang; Sanna, Simone; Norrman, Kion; Christensen, Dennis Valbjørn; Pedersen, Christian \\ Søndergaard; García Lastra, Juan Maria; Traulsen, Marie Lund; Esposito, Vincenzo; Pryds, Nini
}

Published in:

Applied Surface Science

Link to article, DOI:

10.1016/j.apsusc.2018.11.153

Publication date:

2019

Document Version

Peer reviewed version

Link back to DTU Orbit

Citation $(A P A)$ :

Li, Y., Sanna, S., Norrman, K., Christensen, D. V., Pedersen, C. S., García Lastra, J. M., Traulsen, M. L., Esposito, V., \& Pryds, N. (2019). Tuning the stoichiometry and electrical properties of tantalum oxide thin films. Applied Surface Science, 470, 1071-1074. https://doi.org/10.1016/j.apsusc.2018.11.153

\section{General rights}

Copyright and moral rights for the publications made accessible in the public portal are retained by the authors and/or other copyright owners and it is a condition of accessing publications that users recognise and abide by the legal requirements associated with these rights.

- Users may download and print one copy of any publication from the public portal for the purpose of private study or research.

- You may not further distribute the material or use it for any profit-making activity or commercial gain

- You may freely distribute the URL identifying the publication in the public portal 


\section{Accepted Manuscript}

Short Communication

Tuning the stoichiometry and electrical properties of tantalum oxide thin films

Yang Li, Simone Sanna, Kion Norrman, Dennis Valbjørn Christensen, Christian Søndergaard Pedersen, Juan Maria García Lastra, Marie Lund Traulsen, Vincenzo Esposito, Nini Pryds

PII:

DOI:

Reference:

To appear in:

Received Date:

Revised Date:

Accepted Date:

$$
\text { S0169-4332(18)33229-X }
$$

https://doi.org/10.1016/j.apsusc.2018.11.153

APSUSC 40999

\section{Applied Surface Science}

27 June 2018

6 November 2018

19 November 2018

Please cite this article as: Y. Li, S. Sanna, K. Norrman, D. Valbjørn Christensen, C. Søndergaard Pedersen, J. Maria García Lastra, M. Lund Traulsen, V. Esposito, N. Pryds, Tuning the stoichiometry and electrical properties of tantalum oxide thin films, Applied Surface Science (2018), doi: https://doi.org/10.1016/j.apsusc.2018.11.153

This is a PDF file of an unedited manuscript that has been accepted for publication. As a service to our customers we are providing this early version of the manuscript. The manuscript will undergo copyediting, typesetting, and review of the resulting proof before it is published in its final form. Please note that during the production process errors may be discovered which could affect the content, and all legal disclaimers that apply to the journal pertain. 


\section{Tuning the stoichiometry and electrical properties of tantalum oxide thin films}

Yang Li, ${ }^{1}$ Simone Sanna, ${ }^{1}$ Kion Norrman, ${ }^{1}$ Dennis Valbjørn Christensen, ${ }^{1}$ Christian Søndergaard Pedersen, ${ }^{2}$ Juan Maria García Lastra, ${ }^{2}$ Marie Lund Traulsen, ${ }^{1}$ Vincenzo Esposito, ${ }^{1}$ and Nini Pryds ${ }^{1 *}$

${ }^{1}$ Department of Energy Conversion and Storage, Technical University of Denmark, Roskilde, 4000, Denmark

${ }^{2}$ Department of Energy Conversion and Storage, Technical University of Denmark, Kgs. Lyngby, 2800, Denmark

\section{ABSTRACT}

Tantalum oxide has a wide range of applications and has drawn much attention especially for its useful properties in resistive random-access memories, in which the Ta oxide composition plays an important role to control the electrical properties of the $\mathrm{TaO}_{\mathrm{x}}$ thin films. In this paper, we present a way to tune the composition of $\mathrm{TaO}_{\mathrm{x}}$ thin films by varying the oxygen partial pressure during growth using pulsed laser deposition. $\mathrm{TaO}_{\mathrm{x}}$ thin films were deposited at room temperature, under oxygen partial pressures ranging from $10^{-6} \mathrm{mbar}$ to $2 \times 10^{-2} \mathrm{mbar}$. Using angle resolved X-ray photoelectron spectroscopy, we show that the composition of the film varies systematically with the oxygen partial pressure during the film growth. We then correlate the oxygen content with the electrical properties of the film and the results show that the composition has a great influence on the resistivity of the $\mathrm{TaO}_{\mathrm{x}}$ thin films. As the oxygen partial pressure during deposition increases, the percentage of tantalum pentoxide $\left(\mathrm{Ta}_{2} \mathrm{O}_{5}\right)$ as well as the resistivity of the films increases. This experimental approach provides a pathway to control the $\mathrm{TaO}_{\mathrm{x}}$ thin film stoichiometry and its electrical properties during growth.

"Email: nipr@dtu.dk 
Tantalum oxide $\left(\mathrm{TaO}_{\mathrm{x}}\right)$ is a promising candidate for a wide range of applications such as antireflection coatings, ${ }^{1,2}$ optical waveguides, ${ }^{3,4}$ hydrogen generation photocatalysts, ${ }^{5,6}$ and dielectric materials in the microelectronic industry. ${ }^{7,8} \mathrm{TaO}_{\mathrm{x}}$ thin film has recently drawn much attention as a non-volatile memory material which makes it suitable for resistive random access memories (RRAMs). ${ }^{9-12}$ Due to the excellent performances of $\mathrm{TaO}_{\mathrm{x}}$ based RRAMs such as a large endurance of $10^{12}$ cycles $^{11}$ and a fast switching speed of sub-nano second, ${ }^{12}$ it becomes one of the promising materials for memory application. Seen from fabrication point of view, since a high-temperature process is not preferable in complementary metal oxide semiconductor (CMOS) fabrication process, $\mathrm{TaO}_{\mathrm{x}}$ deposited at room temperature is often preferred. The resistive switching phenomenon in this family of materials is usually achieved by partially switching the $\mathrm{TaO}_{\mathrm{x}}$ thin film between a highly resistive state of tantalum pentoxides $\left(\mathrm{Ta}_{2} \mathrm{O}_{5}\right)$ and a more conductive state of $\mathrm{TaO}_{\mathrm{x}<2.5}$ under external electrical field. ${ }^{10,11}$ Understanding the parameters influencing the different phases of $\mathrm{TaO}_{\mathrm{x}}$ and their electrical characteristics is thus essential for memristor device design. The electrical properties of $\mathrm{TaO}_{\mathrm{x}}$ have been found to be greatly influenced by the oxygen content and often very small changes in the deposition parameters cause profound change in the functionality of the film. Tantalum oxide films with different stoichiometry have been reported by using several methods, including thermal oxidation, ${ }^{13}$ sputtering, ${ }^{14-20}$ chemical vapor deposition (CVD) ${ }^{21,22}$ photolysis, ${ }^{23}$ atomic layer deposition (ALD), ${ }^{24,25}$ sol-gel method, ${ }^{26}$ and pulsed laser deposition (PLD) ${ }^{27-34}$. A direct detailed dependence between the stoichiometry of the film and the resistivity of tantalum oxide were so far given mainly for sputtering deposition method ${ }^{17-20}$, but there are no reports on the relation between the deposition condition and the film performance for PLD based samples. Although tantalum oxide thin films deposited by PLD were widely studied, ${ }^{27-39}$ focuse was mainly put on the optical properties, ${ }^{27,28,30,31,33,35,36,38,39}$ leakage current ${ }^{27,29,33,35,36}$ and dielectric constant ${ }^{27}$ of the oxide films. In order to be able to control the exact phases formed during the deposition, understanding of the relation between the film stoichiometry and the deposition conditions, especially the oxygen partial pressure, are desirable. Here we conduct a systematic experimental study to determine and understand the relationship between the Ta oxidation state and the electrical properties of the film. Understanding this will provide a tool to fabricate highly controlled $\mathrm{TaO}_{\mathrm{x}}$ films with tailored properties at room temperature. 
$\mathrm{TaO}_{\mathrm{x}}$ films were deposited using a PLD setup as described elsewhere. ${ }^{40} \mathrm{~A} \mathrm{KrF}$ excimer laser $\left(248 \mathrm{~nm}, 10 \mathrm{~Hz}, 4 \mathrm{~J} / \mathrm{cm}^{2}\right.$ ) was used to ablate a commercial ceramic target of $\mathrm{Ta}_{2} \mathrm{O}_{5}$ (American Elements) with $99.99 \%$ purity and dimensions of $25.4 \mathrm{~mm}$ in diameter and $6 \mathrm{~mm}$ in thickness.

Two types of commercial substrates were used in this study: (1) <100> silicon substrates with $100 \pm 10 \mathrm{~nm}$ silicon di-oxide and $100 \mathrm{~nm}$ sputtered $\mathrm{TiN}$ film on top, labeled as $\mathrm{Si} / \mathrm{SiO}_{2} / \mathrm{TiN}$ substrates and (2) single crystal $<100\rangle \mathrm{MgO}$ substrates. The $\mathrm{TiN}$ layer in the $\mathrm{Si} / \mathrm{SiO}_{2} / \mathrm{TiN}$ substrate acts as a conducting layer, whereas the $\mathrm{MgO}$ substrates were insulating. Both substrates and target were investigated with X-ray diffraction (XRD) to ensure their phase purity prior to the deposition. The deposition was carried out by keeping the target-substrate distance constant at $7.5 \mathrm{~cm}$, while the deposition time was chosen to be either 10 or $60 \mathrm{~min}$ at room temperature. The oxygen partial pressure was varied from $10^{-6}$ mbar (base pressure) to $2 \times 10^{-2}$ mbar and five different values of oxygen partial pressures were used in total. X-ray diffraction (XRD) and scanning electron microscope (SEM) were employed on all films to characterize the crystalline quality and the morphology of the films. The oxidation states of $\mathrm{Ta}$ in the $\mathrm{TaO}_{\mathrm{x}}$ films were determined by angle resolved X-ray photoelectron spectroscopy (ARXPS). The ARXPS analyses were performed on a ESCALAB $\mathrm{XI}^{+} \mathrm{X}$-ray photoelectron spectrometer microprobe (Thermo Fisher Scientific, East Grinstead, U.K.) using a monochromatic Al-Ka X-ray source with a 900 $\mu \mathrm{m}$ spot size. A combined ion/electron gun (i.e. a dual beam source) was used to control sample charging. The electrical conductivity was measured on a rectangular shaped sample $(10 \mathrm{~mm} \times 10$ $\mathrm{mm}$ ) in a Van der Pauw configuration using a station probe (Imina).

Figure 1 (a) and (b) show the schematic configurations of the deposited films together with a micrograph showing a cross-sectional SEM image of the $\mathrm{TaO}_{\mathrm{x}}$ film deposited on TiN substrate (at $\mathrm{P}_{\mathrm{O} 2}=10^{-6}$ mbar, room temperature). The $\mathrm{TaO}_{\mathrm{x}}$ thin films deposited at $\mathrm{P}_{\mathrm{O} 2}=10^{-6}$ mbar on $\mathrm{Si} / \mathrm{SiO}_{2} / \mathrm{TiN}$ and $\mathrm{MgO}$ substrates show a typical similar surface morphology, as illustrated in Figure 1 (c) and (d), respectively. $\mathrm{TaO}_{\mathrm{x}}$ thin films grown at different oxygen partial pressures all show similar microstructures. $\mathrm{XRD}$ of $\mathrm{TaO}_{\mathrm{x}}$ films deposited at different oxygen partial pressure shows that all the films deposited on top of the $\mathrm{Si} / \mathrm{SiO}_{2} / \mathrm{TiN}$ substrate have no distinct diffraction peak other than the one belong to substrate peaks, indicating the existence of an amorphous structure (supplementary material, Figure S1). 
Since the memristors operate at room temperature, the resistivity of different $\mathrm{TaO}_{\mathrm{x}}$ films were measured at this temperature. Figure 2 shows the results of the room-temperature resistivity of $\mathrm{TaO}_{\mathrm{x}}$ thin films grown on $\mathrm{MgO}$ substrates for $60 \mathrm{~min}$ as a function of oxygen partial pressure in the PLD chamber. The resistivity of the films did not show very minor anisotropy in the plane of the film. The result shows that the resistivity increases from $0.33 \Omega \cdot \mathrm{cm}$ up to $2.34 \mathrm{k} \Omega \cdot \mathrm{cm}$ as the oxygen partial pressure increases from $10^{-6}$ mbar to $5 \times 10^{-3}$ mbar. The resistivity of the $\mathrm{TaO}_{\mathrm{x}}$ film grown at an oxygen partial pressure of $2 \times 10^{-2}$ mbar was high above the measurement limit. The oxygen partial pressure can therefore be used as a convenient knob to tune the conductivity towards a more insulating phase as the pressure is increased.

The chemical composition of the $\mathrm{TaO}_{\mathrm{x}}$ thin films were examined by ARXPS. High resolution local binding energy spectra, as shown in Figure 3, were obtained for Ta-4f using $20 \mathrm{eV}$ detector pass energy, $50 \mathrm{~ms}$ dwell time, 0.02 energy step size, and collected over 5 scans. Fitting analysis of the Ta $4 \mathrm{f}$ peaks and thus quantification of the Ta oxidation states is based on the approach by Simpson et al. ${ }^{41}$. Peaks were fitted using a 38\% Lorentzian/Gaussian function, a 4f5/4f7 spin orbit splitting of $1.9 \mathrm{eV}$, and a $4 \mathrm{f5} / 4 \mathrm{f} 7$ height ratio of 0.788 . Figure 3 presents Ta $4 \mathrm{f}$ ARXPS spectra obtained at an emission angle of $\theta=0^{\circ}$ relative to the perpendicular direction to the surface of the sample (i.e. maximum escape depth), showing the main $\mathrm{Ta}^{5+}$ peak together with lower oxidation states. These are $\mathrm{Ta}^{4+}, \mathrm{Ta}^{3+}, \mathrm{Ta}^{2+}, \mathrm{Ta}^{1+}$, and $\mathrm{Ta}^{0}$ representing $\mathrm{TaO}_{2}, \mathrm{Ta}_{2} \mathrm{O}_{3}, \mathrm{TaO}$, $\mathrm{Ta}_{2} \mathrm{O}$, and Ta metal, respectively. The main peaks observed are the Ta $4 \mathrm{f} 7 / 2$ and the $\mathrm{Ta} 4 \mathrm{f} 5 / 2$ peaks at binding energies of $26.9 \pm 0.1 \mathrm{eV}$ and $28.8 \pm 0.1 \mathrm{eV}$, respectively. This confirms that most of the deposited thin films are composed of $\mathrm{Ta}_{2} \mathrm{O}_{5}$. The fit of the $\mathrm{Ta} 4 \mathrm{f}$ peaks and thus quantification of the Ta oxidation states is based on the approach by Simpson et al. ${ }^{41}$. (The comparison between the binding energies for each oxidation states used in the work of Simpson et al. $^{41}$ and this paper is shown in the supplementary material Table S1.)

In order to investigate the composition homogeneity along the film growth direction and the surface oxidation conditions of the $\mathrm{TaO}_{\mathrm{x}}$ thin films, ARXPS were carried out and the emission angles $\theta$, relative to the perpendicular direction of the surface of the sample, vary from $0^{\circ}$ to $90^{\circ}$ (gracing angle), which corresponds to the maximum probe depth of $\sim 10 \mathrm{~nm}$ and the upper surface layer of the $\mathrm{TaO}_{\mathrm{x}}$ thin films, respectively. As show in Figure 4 (a), for $\mathrm{TaO}_{\mathrm{x}}$ thin films deposited under high oxygen partial pressure $\left(5 \times 10^{-3}\right.$ mbar $)$ for a short time (10 min) 
corresponding to a film thickness of $23 \pm 4 \mathrm{~nm}$, the composition of $\mathrm{TaO}_{\mathrm{x}}$ thin film is homogeneous for all emission angles, which means a homogeneous Ta oxidation states composition from surface to approximately $10 \mathrm{~nm}$ deep under the surface. As compared to the $\mathrm{TaO}_{\mathrm{x}}$ deposited for the same time but under a lower oxygen partial pressure (10-6 mbar) corresponding to a film thickness of $6 \pm 1 \mathrm{~nm}$, the composition of $\mathrm{Ta}_{2} \mathrm{O}_{5}$ increases as the emission angle increases, which indicate a higher $\mathrm{Ta}_{2} \mathrm{O}_{5}$ composition near the film surface, as shown in Figure 4 (b). This finding is in consistence with the work of Sharath et al. ${ }^{42}$ Furthermore, as the thickness of the films increase, the composition of the thin films deposited at high oxygen partial pressure is not homogeneous any longer from surface to approximately $10 \mathrm{~nm}$ deep under the surface and a composition gradient along the film growth direction can be seen for films deposited at both high and low oxygen partial pressure, as shown in Figure 4 (c) and (d), respectively.

Figure 5 illustrates the Ta oxidation states in the $\mathrm{TaO}_{\mathrm{x}}$ films as a function of oxygen partial pressure. The percentage of Ta oxidation states in the $\mathrm{TaO}_{\mathrm{x}}$ films are obtained from the XPS data taken at an emission angle of $0^{\circ}$. The percentage of $\mathrm{Ta}^{5+}\left(\mathrm{Ta}_{2} \mathrm{O}_{5}\right)$ increases from 75 at.\% to 95 at. $\%$ as the oxygen partial pressure increases from $10^{-6}$ mbar to $2 \times 10^{-2}$ mbar while the contribution from the lower oxidation state reduces. By comparing the XPS results, it is clear that it requires very low oxygen partial pressures to form lower oxidation state than the $\mathrm{Ta}^{5+}$ in a significant concentration. Comparing the XPS results of samples deposited at the same oxygen partial pressure, but different deposition duration of $60 \mathrm{~min}$ and $10 \mathrm{~min}$ (supplementary material S2), the results indicate that combining long deposition duration with low oxygen partial pressure provides the most efficient way to form lower oxidation states in significant concentrations.

In summary, we demonstrated the influence of oxygen partial pressure during PLD growth on the properties and stoichiometry of $\mathrm{TaO}_{\mathrm{x}}$ films. This was used to tune the oxygen content in the film and therefore the resistivity of the $\mathrm{TaO}_{\mathrm{x}}$ films. Our approach suggests that the future design of the desired initial state of the memory devices which depend very much of the phases used can be attained by choosing the right deposition parameters. 


\section{FIGURES}

(a)
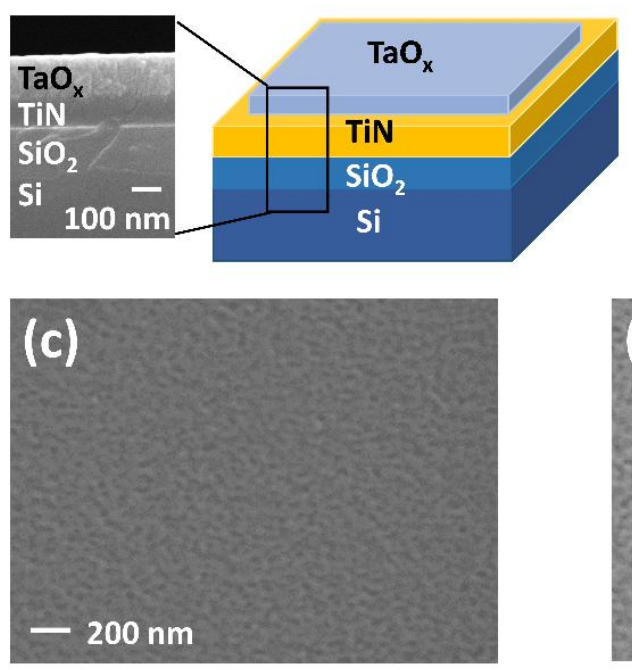

$\mathrm{TaO}_{x}$ on $\mathrm{Si} / \mathrm{SiO}_{2} / \mathrm{TiN}$ substrate (b)
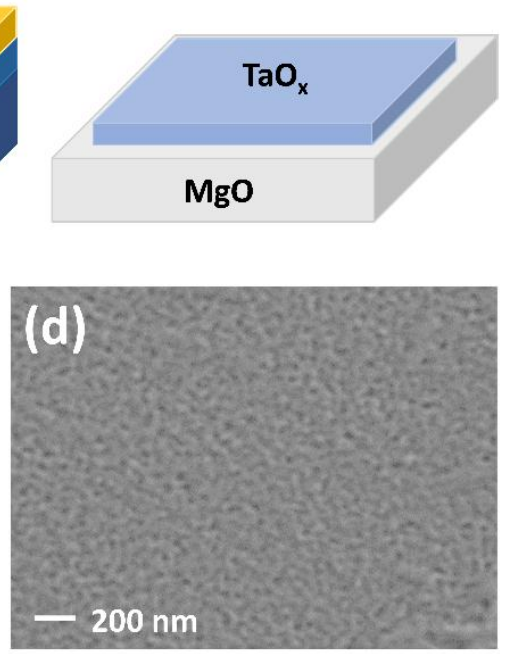

$\mathrm{TaO}_{\mathrm{x}}$ on $\mathrm{MgO}$ substrate

Figure 1. (a) A schematic illustration of $\mathrm{TaO}_{\mathrm{x}}$ film deposited on $\mathrm{Si} / \mathrm{SiO}_{2} / \mathrm{TiN}$ substrate. The inset shows a cross sectional SEM image of the film stack. (b) A schematic illustration of $\mathrm{TaO}_{\mathrm{x}}$ film deposited on $\mathrm{MgO}$ (100) substrate. (c) SEM picture showing the surface of $\mathrm{TaO}_{\mathrm{x}}$ film deposited on $\mathrm{Si} / \mathrm{SiO}_{2} / \mathrm{TiN}$ substrate. (d) SEM picture showing the surface of $\mathrm{TaO}_{\mathrm{x}}$ film deposited on $\mathrm{MgO}(100)$ substrate. The $\mathrm{TaO}_{\mathrm{x}}$ films shown here are all deposited under $10^{-6} \mathrm{mbar}$ at room temperature. 


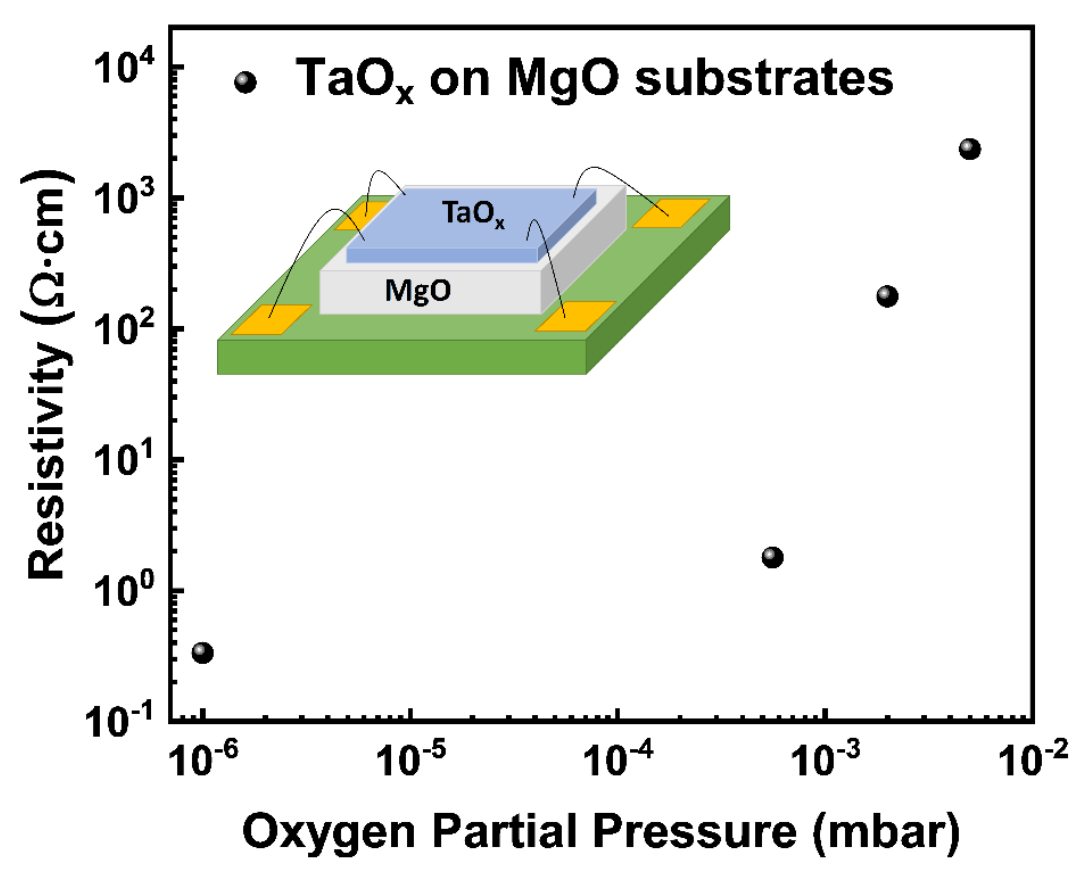

Figure 2. The relation between $\mathrm{TaO}_{\mathrm{x}}$ thin film resistivity and oxygen partial pressure during deposition. The inset figure shows the van der Pauw configuration for resistivity test. Since the figure is plotted in double logarithmic coordinates, the error bars are not included due to lack of visibility. The relative standard deviation $(\sigma / \mu)$ of the resistivity is smaller than $13 \%$. 

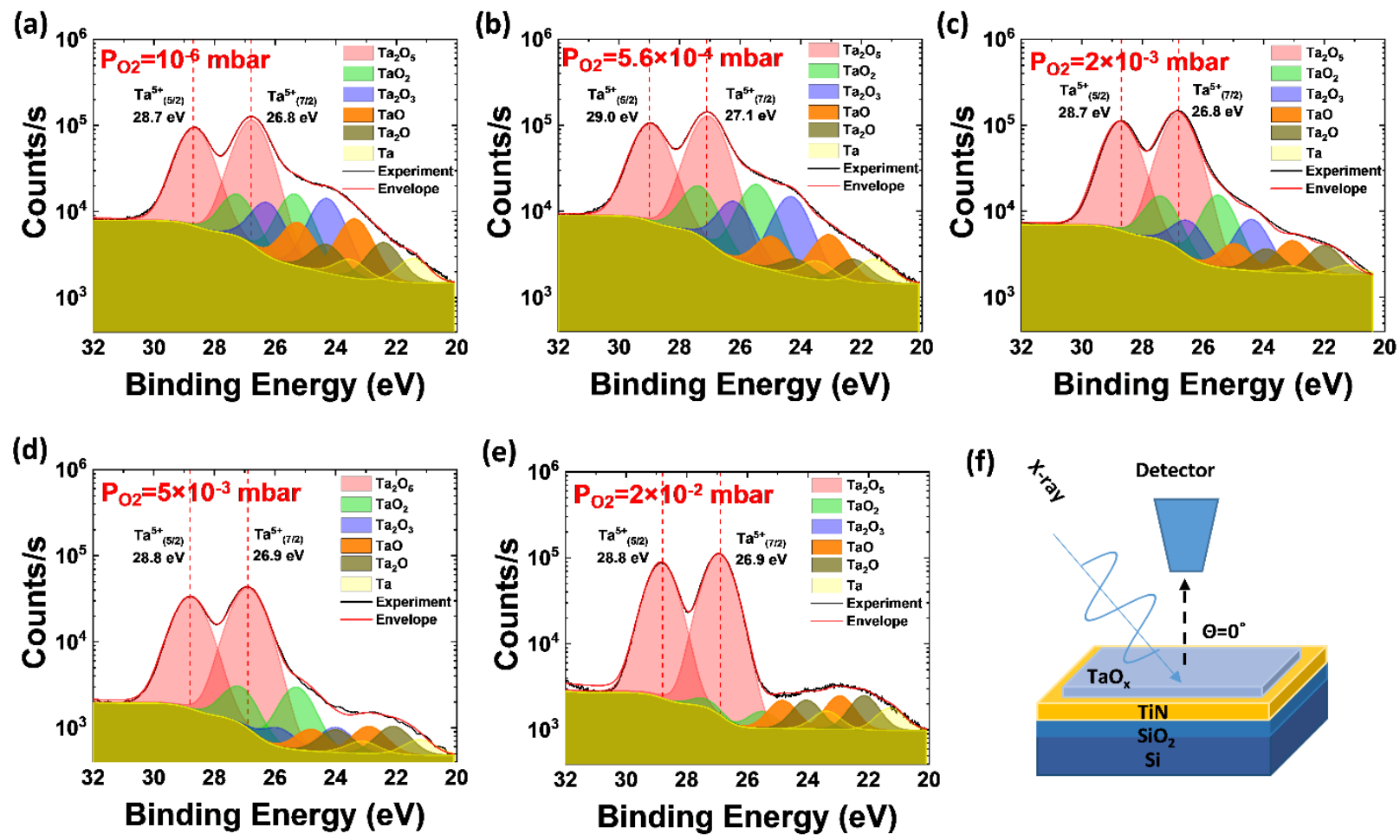

Figure $3 \mathrm{Ta} 4 \mathrm{f}$ XPS spectra of $\mathrm{TaO}_{\mathrm{x}}$ thin films deposited for 60 min under different oxygen partial pressure of: (a) $\mathrm{P}_{\mathrm{O} 2}=10^{-6}$ mbar, (b) $\mathrm{P}_{\mathrm{O} 2}=5.6 \times 10^{-4}$ mbar, (c) $\mathrm{P}_{\mathrm{O} 2}=2 \times 10^{-3}$ mbar, (d) $\mathrm{P}_{\mathrm{O} 2}=5 \times 10^{-3}$ mbar, and (e) $\mathrm{P}_{\mathrm{O} 2}=2 \times 10^{-2}$ mbar. The solid black lines are the experiment XPS spectra data and the solid red lines are the fitting envelopes of the XPS spectra data. 
(a)

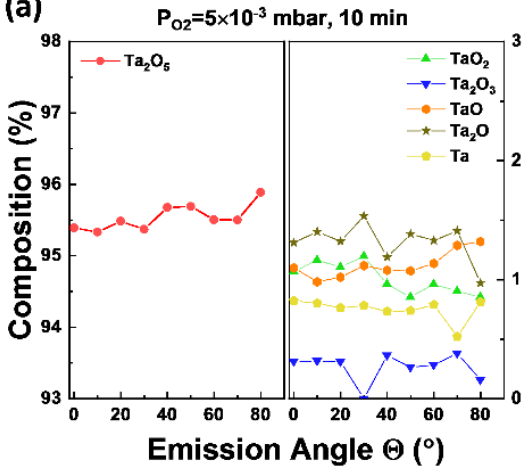

(c)

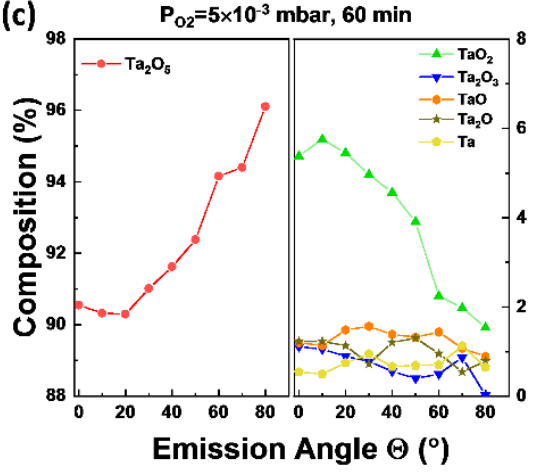

(b)

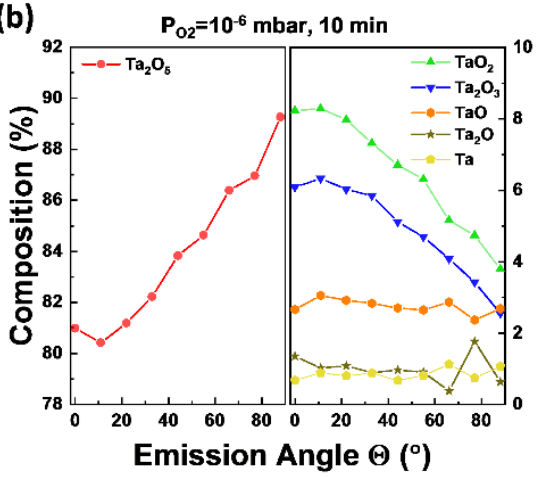

(d)

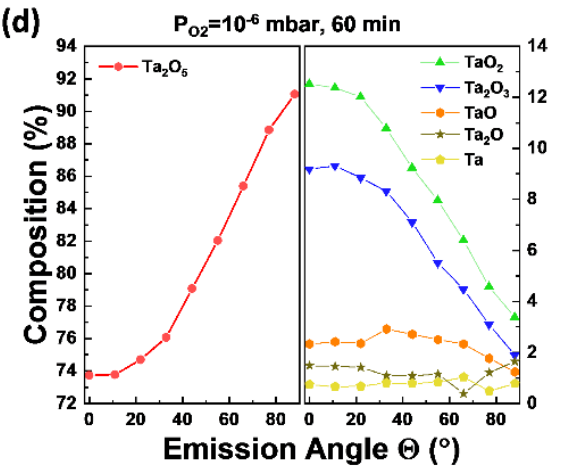

(e)

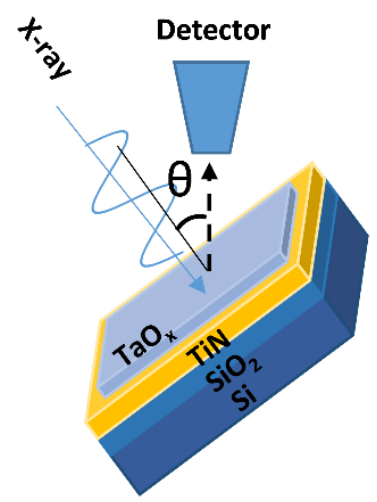

Figure 4 The Ta oxidation states of $\mathrm{TaO}_{\mathrm{x}}$ films deposited under different conditions revealed by ARXPS spectra. (a) oxygen partial pressure of $\mathrm{P}_{\mathrm{O} 2}=5 \times 10^{-3}$ mbar for deposition time of $10 \mathrm{~min}$, (b) oxygen partial pressure of $\mathrm{P}_{\mathrm{O}_{2}}=10^{-6}$ mbar for deposition time of $10 \mathrm{~min}$, (c) oxygen partial pressure of $\mathrm{P}_{\mathrm{O} 2}=5 \times 10^{-3} \mathrm{mbar}$ for deposition time of $60 \mathrm{~min}$, and (d) oxygen partial pressure of $\mathrm{P}_{\mathrm{O} 2}=10^{-6}$ mbar for deposition time of 60 min. (e) is a schematic illustration of the principle of ARXPS. The angle $\theta$ is the emission angle relative to the perpendicular direction of the surface of the sample. By changing the emission angle, the sampling depth decreases from $\sim 10 \mathrm{~nm}$ at $\theta=0^{\circ}$ to the very surface of the film at $\theta=90^{\circ}$. 


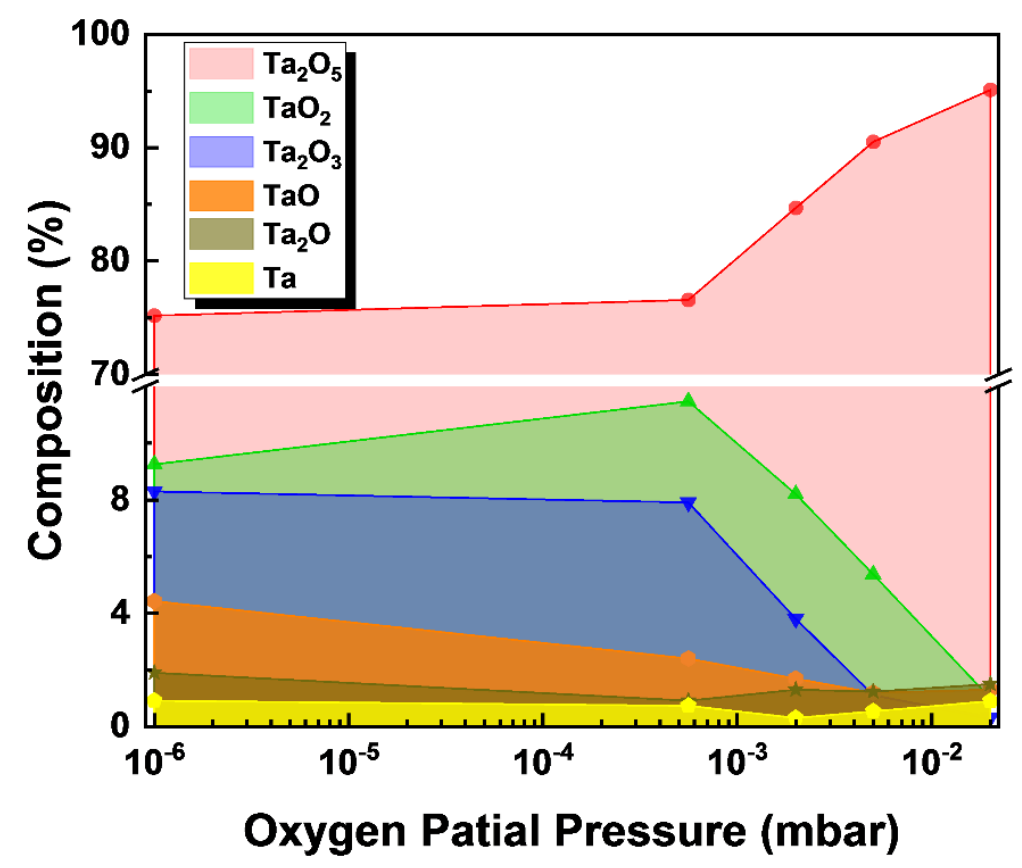

Figure 5. The Ta oxidation states inside $\mathrm{TaO}_{\mathrm{x}}$ thin films deposited under different oxygen partial pressure for $60 \mathrm{~min}$ at room temperature.

\section{AUTHOR INFORMATION}

Corresponding author

*Email: nipr@dtu.dk

\section{ACKNOWLEDGMENT}

The authors thank the support from the Independent Research Fund Denmark, Grant No. 611100145B

\section{REFERNCES}

${ }^{1}$ C.T. Wu, F.H. Ko, and C.H. Lin, Appl. Phys. Lett. 90, 2005 (2007). 
${ }^{2}$ F. Rubio, J. Denis, J.M. Albella, and J.M. Martinez-Duart, Thin Solid Films 90, 405 (1982).

${ }^{3}$ T. Chen Sverre, J.R.C. Woods, P. Hua, J.S. Wilkinson, A.C. Tropper, V. Apostolopoulos, and E.A. Shaw, Vert. Extern. Cavity Surf. Emit. Lasers VIII 29 (2018).

${ }^{4}$ A. Aghajani, G.S. Murugan, N.P. Sessions, V. Apostolopoulos, and J.S. Wilkinson, Opt. Lett. 40, 2549 (2015).

${ }^{5}$ V.S. Souza, J.D. Scholten, D.E. Weibel, D. Eberhardt, D.L. Baptista, S.R. Teixeira, and J. Dupont, J. Mater. Chem. A 4, 7469 (2016).

${ }^{6}$ M.M. Momeni, M. Mirhosseini, M. Chavoshi, and A. Hakimizade, J. Mater. Sci. Mater. Electron. 27, 3941 (2016).

${ }^{7}$ A.I. Kingon, J.P. Maria, and S.K. Streiffer, Nature 406, 1032 (2000).

${ }^{8}$ C. Chaneliere, J.L. Autran, R.A.B. Devine, and B. Balland, Mater. Sci. Eng. R Reports 22, 269 (1998).

${ }^{9}$ I.T. Wang, Y.C. Lin, Y.F. Wang, C.W. Hsu, and T.H. Hou, Tech. Dig. - Int. Electron Devices Meet. IEDM 2015-Febru, 28.5.1 (2015).

${ }^{10}$ M.J. Lee, C.B. Lee, D. Lee, S.R. Lee, M. Chang, J.H. Hur, Y.B. Kim, C.J. Kim, D.H. Seo, S. Seo, U.I. Chung, I.K. Yoo, and K. Kim, Nat. Mater. 10, 625 (2011).

${ }^{11}$ Y.-B. Kim, S.R. Lee, D. Lee, C.B. Lee, M. Chang, J.H. Hur, M.-J. Lee, G.-S. Park, C.J. Kim, U.-I. Chung, I.-K. Yoo, and K. Kim, Symp. VLSI Technol. - Dig. Tech. Pap. 52 (2011). 
12 A.C. Torrezan, J.P. Strachan, G. Medeiros-Ribeiro, and R.S. Williams, Nanotechnology 22, (2011).

${ }^{13}$ G.S. Oehrlein, F.M. D’Heurle, and A. Reisman, J. Appl. Phys. 55, 3715 (1984).

${ }^{14}$ H. Demiryont, J.R. Sites, and K. Geib, Appl. Opt. 24, 490 (1985).

15 A.J. Lohn, J.E. Stevens, P.R. Mickel, and M.J. Marinella, Appl. Phys. Lett. 103, (2013).

${ }^{16}$ M.T. Brumbach, P.R. Mickel, A.J. Lohn, A.J. Mirabal, M.A. Kalan, J.E. Stevens, and M.J. Marinella, J. Vac. Sci. Technol. A Vacuum, Surfaces, Film. 32, 051403 (2014).

${ }^{17}$ D. Gerstenberg and C.J. Calbick, J. Appl. Phys. 35, 402 (1964).

${ }^{18}$ I. Goldfarb, F. Miao, J.J. Yang, W. Yi, J.P. Strachan, M.X. Zhang, M.D. Pickett, G. MedeirosRibeiro, and R.S. Williams, Appl. Phys. A Mater. Sci. Process. 107, 1 (2012).

${ }^{19}$ F. Miao, W. Yi, I. Goldfarb, J.J. Yang, M.X. Zhang, M.D. Pickett, J.P. Strachan, G. MedeirosRibeiro, and R.S. Williams, ACS Nano 6, 2312 (2012).

${ }^{20}$ J.E. Stevens, A.J. Lohn, S.A. Decker, B.L. Doyle, P.R. Mickel, and M.J. Marinella, J. Vac. Sci. Technol. A Vacuum, Surfaces, Film. 32, 021501 (2014).

${ }^{21}$ L. Corp, S. Joseph, J. Wiley, N. York, W.R. Hitchens, W.C. Krusell, and D.M. Dobkin, Mater. Sci. Eng. R 22, 269 (1993).

${ }^{22}$ S.R. Jeon, S.W. Han, and J.W. Park, J. Appl. Phys. 77, 5978 (1995).

${ }^{23}$ Y. Imai, A. Watanabe, M. Mukaida, K. Osato, and T. Kameyama, Thin Solid Film. 261 261, 
76 (1995).

${ }^{24}$ K. Kukli, M. Ritala, and M. Leskela, J. Electrochem. Soc. 142, 1670 (1995).

${ }^{25}$ K. Kukli, J. Aarik, A. Aidla, O. Kohan, T. Uustare, and V. Sammelselg, Thin Solid Films 260, 135 (1995).

${ }^{26}$ T. Ohishi, S. Maekawa, and A. Katoh, J. Non. Cryst. Solids 147-148, 493 (1992).

${ }^{27}$ Zhou Mingfei, Fu Zhengwen, Yang Haijun, Zhang Zhuangjian, and Qin Qizong, Appl. Surf. Sci. 108, 399 (1997).

${ }^{28}$ S. Boughaba, M.U. Islam, G.I. Sproule, and M.J. Graham, Surf. Coatings Technol. 120-121, 757 (1999).

${ }^{29}$ Q. Qin and Z. Fu, Adv. Mater. 11, 1119 (1999).

${ }^{30}$ J.-Y. Zhang and I.W. Boyd, Appl. Surf. Sci. 168, 234 (2000).

${ }^{31}$ S. Boughaba, G.I. Sproule, J.P. McCaffrey, M. Islam, and M.J. Graham, Thin Solid Films 358, 104 (2000).

${ }^{32}$ T. Hino, M. Nishida, and T. Araki, Surf. Coatings Technol. 149, 1 (2002).

${ }^{33}$ T. Hino, S. Mustofa, M. Nishida, and T. Araki, Appl. Surf. Sci. 189, 1 (2002).

${ }^{34}$ F. Kurnia, Hadiyawarman, C.U. Jung, R. Jung, and C. Liu, Phys. Status Solidi - Rapid Res. Lett. 5, 253 (2011). 
35 J.-Y. Zhang, Q. Fang, and I.W. Boyd, Appl. Surf. Sci. 138-139, 320 (1999).

${ }^{36}$ J.-Y. Zhang and I.W. Boyd, Appl. Phys. A Mater. Sci. Process. 70, 657 (2000).

${ }^{37}$ O.K. Donaldson, K. Hattar, J.R. Trelewicz, and E.I.C. Johnson, J. Am. Ceram. Soc. 99, 3775 (2016).

${ }^{38}$ G. W., Appl. Opt. 28, 2806 (1989).

${ }^{39}$ Y. Nishimura, U. Hiroki, T. Ochiai, and M. Tsuji, Appl. Surf. Sci. 79-80, 165 (1994).

${ }^{40}$ D. V. Christensen, F. Trier, M. Von Soosten, G.E.D.K. Prawiroatmodjo, T.S. Jespersen, Y.Z. Chen, and N. Pryds, Appl. Phys. Lett. 109, (2016).

${ }^{41}$ R. Simpson, R.G. White, J.F. Watts, and M.A. Baker, Appl. Surf. Sci. 405, 79 (2017).

${ }^{42}$ S.U. Sharath, M.J. Joseph, S. Vogel, E. Hildebrandt, P. Komissinskiy, J. Kurian, T. Schroeder, and L. Alff, Appl. Phys. Lett. 109, 1 (2016).

43 R.J. Bondi, M.P. Desjarlais, A.P. Thompson, G.L. Brennecka, and M.J. Marinella, J. Appl. Phys. 114, (2013). 


\section{Highlights}

Understanding the different phases of $\mathrm{TaO}_{\mathrm{x}}$ and their electrical characteristics is essential for future application of these materials in memristor devices but also for a wider range of other applications. However, so far there is no detailed work about the correlation between the process parameters such as oxygen partial pressure during deposition using PLD, the exact composition of $\mathrm{TaO}_{\mathrm{x}}$ thin films and their respective electrical properties. Here, we conducted a detailed investigation to understand the relation between the oxygen partial pressure and the properties of the film. 